\title{
THE MEANING OF YES AND NO \\ IN ENGLISH AND KOREAN
}

\author{
Soon-Ham Park Kim \\ University of Michigan
}

1. INTRODUCTION.

"Don't you know him?"

"No, I do! I have known him since last year."

Obviously, the answer should have been "Yes, I do;" and this is not a difficult part of English grammar for an English speaker to master. But when a cultural boundary is crossed, in certain languages "No, I do" is correct. Thus, a non-English speaker with such a different linguistic background, who is learning English as a foreign language, will often directly "translate" into English the answers he has formed in his own linguistic frame, and he will invariably leave puzzled and confused faces around him.

One such case occurs between Korean and English; another between Japanese and English. A survey of the current articles indicates the absence of any specific treatment of this subject, although English textbooks for foreigners contain sections for general question-answer drills and a casual mention of the subject may be found in some travel manuals.

This paper deals with a contrastive analysis of uses of the response words yes and no in English and Korean. Aimed primarily at Korean students of English, and their teachers, it provides some suggested lesson plans which others may also find helpful.

\section{THE DIFFERENCE BETWEEN ENGLISH AND KOREAN USES} OF YES AND NO.

In English, the response words are used on the basis of the status of the fact: yes for affirmative facts, and no for negative facts. In Korean, they are used on the basis of the relationship between the fact and the form of the preceding stimulus sentence (question, command, or statement): yes for affirmative relationship, that is, agreement between the statuses of the two elements, and no for negative relationship, disagreement. 
To support this general description, illustrative figures are presented below with examples: ${ }^{1}$

\section{ENGLISH}

Stimulus Sentence Fact Response Supplement to Response

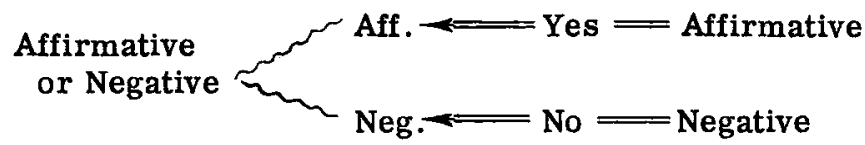

Example: (Question) Do you like it? (or) Don't you like it?

(Fact Aff.) Yes, I do.

(Fact Neg.) No, I don't.

\section{KOREAN}

A. When the form of the stimulus sentence is affirmative: ${ }^{2}$
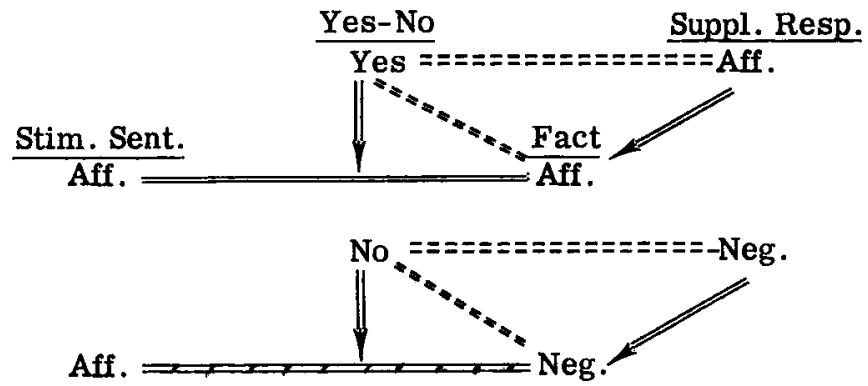

Example: (Question) kikat coa hasimniKa? ${ }^{3}$ Do you like it?

(Fact Aff.) ne, Coa hamnita. Yes, I do.

(Fact Neg.) aniyo, $a n^{4}$ coa hamnita. No, I don't.

\footnotetext{
I Key to the meaning of symbols:

นn Irrelevant

$=$ Equal status

Equal status (and refers to)

${ }^{2}$ Key to the meaning of symbols:

$=z=E=$ Equal status with different referents.

Unequal status.

$3 / \mathbf{k} /$ is lightly aspirated; $/ K /$ is unaspirated.

$4 / \mathrm{an} /$ which is a short form of /ani/ is an adverb of negation, and constructs one of the Korean negative expressions by preceding the main verb (in the present example).
} 
B. When the form of the stimulus sentence is negative:
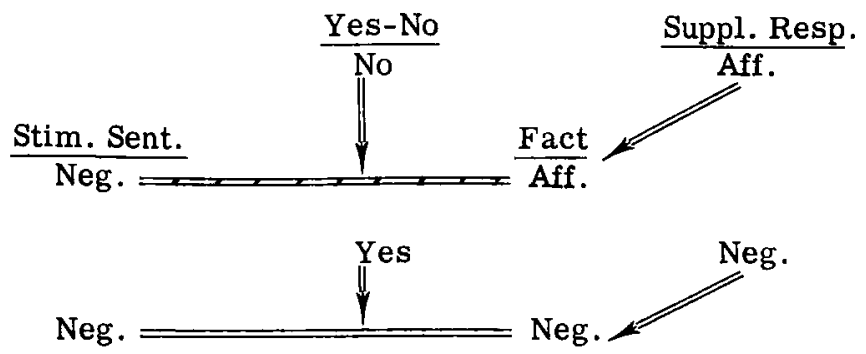

Example: (Question) kikatan coa hasimniKa? Don't you like it? (Fact Aff.) aniyo, coa hamnita. No, I do. (Fact Neg.) ne, an coa hamnita. Yes, I don't.

The features characteristic of each language, illustrated by the figures above, can be restated as follows: 1) In English, the form of the stimulus sentence is irrelevant to selection of a response word, yes or no. In Korean, it is significant. 2) In English, the response words represent statuses of facts; the status of the response word and of the facts are always identical; and statuses of the response words and the supplementary response sentences are dependent upon each other and are always identical. Hence, the forms of the three elements-fact, response word, and supplementary part of the response-are always in the same status.

In Korean, the response words represent whether the statuses of the stimulus sentence and the fact are the same or different. The statuses of the response words and the supplementary response sentences are independent of each other, each referring to a different thing. When the form of the stimulus sentence is affirmative, there exists a formal agreement between the statuses of the three elements-fact, response word, and supplementary part of the response. Therefore, there is no difference on the surface in this case between English and Korean in the uses of the response words. On the other hand, when the form of the stimulus sentence is negative, the statuses of the response words are always in contradiction to the status of the facts and of the supplementary response sentences. Here appears the difference in behavior between the English speaker and the Korean speaker learning English; and this is what gives rise to misunderstanding between the two.

There are two exceptional cases, however, to the general rule of the Korean use of yes and no described above. Some 
questions with an implication of politeness often appear in a negative form such as "com to an tisikeSimniKa?" 5 (Wouldn't you like to take some more?)" And also some exclamatory expressions appear in a negative question form such as "co $\epsilon$ Ł̇am $^{6}$ yePíči anni? ${ }^{7}$ (Isn't that child very pretty?)." These questions are distinguished from simple fact-inquiring negative questions by means of the situation, the context and the speaker's tone. To this type of question, Korean speakers respond in the same form as is used in English; that is, to the first question the answer would be either "ne, cokimmanta tilciyo. (Yes, I'd like to take just a little more.)" or "aniyo, nəmu manhi məkəSimnita. (No, I've eaten too much.)" To the second question, the answer would be either "in, Eam yePita (Yah, very pretty)" or "ani, pyallo ${ }^{8}$ (No, not very)." Regarding these exceptions, a further comment will be briefly made in Section 3.1 .

3. COMPARISON OF THE ENGLISH AND KOREAN USES OF THE RESPONSE WORDS YES AND NO IN RESPONSES TO SPECIFIC TYPES OF SENTENCES. The present section is divided into five subsections, arranged on the basis of the degree to which the response words yes and no are required for specific types of stimulus sentences; for example, the stereotyped yes-no questions precede other less stereotyped questions, commands, or statements.

The comparison is carried on mainly through charts of English and Korean sample responses. The Korean examples represent two things: 1) The response patterns involving the words yes and no used by Korean speakers in Korean conversations. 2) The wrong patterns frequently used by Korean speakers learning English in English conversations: when the form of the stimulus sentence is affirmative, no problem or error arises; when the stimulus sentence is negative, the patterns thus simply transferred from the native language are erroneous.

In the following subsections, the specific meaning of yes and $n o$ in each case is pointed out when necessary only for Korean, since the simple principle of "fact-basis" for the English uses of the response words requires no further comment on

$5 / \mathrm{s} /$ is lax; $/ \mathrm{S} /$ is tense.

$6 / \check{c} /$ is lightly aspirated; $/ \check{\epsilon} /$ is heavily aspirated.

7 /an-/ in this example is a short form of the stem /aniha-/ of the auxiliary adjective of negation, and constructs another type of Korean negative expression by following the main adjective.

$8 / \mathrm{p} /$ is lightly aspirated; $/ \mathrm{P} /$ is unaspirated. 
subtle semantic differences. Korean examples in the charts are presented only in English translation for the sake of simplicity.

\subsection{IN RESPONSES TO SIMPLE YES-NO QUESTIONS WHICH} CONTAIN A SINGLE STATUS. The response words yes and no are indispensable in responses to yes-no questions as their self-explanatory name indicates.

In Korean, yes and no mean "affirma tion" and "negation," respectively, of the status appearing in the form of the preceding question.

\begin{tabular}{l|c|l|l}
\hline STIMULUS SENTENCE & \multirow{2}{*}{ FACT } & \multicolumn{2}{|c}{ RESPONSE } \\
\cline { 1 - 3 } Simple Yes-No Question & & English & \multicolumn{1}{|c}{ Korean } \\
\hline (Aff.) & Aff. & Yes, I am. & Yes, I am. \\
Are you a student? & Neg. & No, I am not. & No, I am not. \\
\hline (Neg.) & Aff. & Yes, I am. & No, I am. \\
Aren't you a student? & Neg. & No, I am not. & Yes, I am not. \\
\hline
\end{tabular}

The same chart can be applied to yes-no questions which appear in the statement pattern with rising intonation: "You are a student?" "You are not a student?"

To what has been generalized in the above chart, there are three exceptions. Two of them are the cases (1) when the question is put in the negative implying politeness as in such questions as "Won't you come with us?" and "Wouldn't you like to stay here with us tonight?" and (2) when the question is put also in the negative containing an exclamatory implication as in such questions as "Isn't she pretty? (!)" and "Wasn't it a lovely sight? (!)" To these negative questions, which are not for simple fact-inquiring, Korean learners of English are able to answer with ease, or happen to answer, in the correct English pattern by using yes for affirmative intention or fact and no for negative. This easily managed correctness is primarily due to the exceptional response patterns within the Korean language itself, as mentioned in the preceding section.

The third exception is related specifically to the word mind used as a verb in such a question as "Do you mind if I smoke?" When asked such a question as this, Korean speakers learning English are frequently heard to answer "Yes, please," instead of "No, I don't," which is the correct form in English and also is the form expected from the pattern of other answers for 
affirmative yes-no questions. To understand this mistake, two factors may be considered: (1) The fact that the word mind has a negative meaning without any negative syntactical construction causes confusion on the part of Korean speakers and gives them some difficulty in learning the proper thing to say. This difficulty, in turn, is due to the fact that there is no exactly equivalent lexical item in Korean. (2) In spite of the original ques tion form, which is rather confusing as described above, the situation is clear; and the question is interpreted by Korean speakers simply as "May I smoke?" or "Is it all right if I smoke?" which is in affirmative yes-no question form and normally elicits from them the answer "Yes, please," as long as they do not object to the other person's smoking.

\subsection{IN RESPONSES TO COMPLEX YES-NO QUESTIONS WHICH} CONTAIN TWO OPPOSITE STATUSES ("ATTACHED QUESTIONS'). The response words yes and no are also indispensable in responses to attached questions.

In reaction to attached questions, the attention of Korean speakers tends to be drawn only to the first part of the question, that is, the statement, as far as the selection of a response word is concerned. The second part of the question, that is, the genuine question sentence, serves them merely as a question signal.

The native language factor to be considered here is that the question part of English attached questions corresponds to an inflectional ending of a verb, adjective, or copula in Korean questions of this type. The following is a pair of such examples:

\section{ENGLISH}

You like music, don't you?

You don't like music, do you?

\section{KOREAN}

You music like-infl.?

You music don't like-infl.?

The inflectional ending which appears in the Korean attached questions does not show any affirmative or negative status. Therefore, Korean speakers simply disregard the status which appears in the question part of a complex yes-no question in English; and accordingly their response will be based on the form of the statement that precedes the question. 


\begin{tabular}{|c|c|c|c|}
\hline STIMULUS SENTENCE & \multirow{2}{*}{ FACT } & \multicolumn{2}{|c|}{ RESPONSE } \\
\hline Complex Yes-No Question & & English & Korean \\
\hline (Neg.) & Aff. & Yes, I do. & Yes, I do. \\
\hline You like music, don't you? & Neg. & No, I don't. & No, I don't. \\
\hline (Neg.) & Aff. & Yes, I do. & No, I do. \\
\hline You don't like music, do y & eg. & No, I don't. & Yes, I don't. \\
\hline
\end{tabular}

3.3. IN RESPONSES TO COMMANDS. The response words yes and no may occur in oral responses to commands accompanying action responses. In Korean, yes and no imply the intention of "obedience" and of "disobedience" to the commands respectively.

\begin{tabular}{l|c|c|c}
\hline \multicolumn{1}{c|}{ STIMULUS SENTENCE } & FACT & \multicolumn{2}{|c}{ RESPONSE } \\
\cline { 3 - 4 } Command & English & Korean \\
\hline (Aff.) & Aff. & Yes, I will. & Yes, I will. \\
Do your homework now. & Neg. & No, I won't. & No, I won't. \\
\hline (Neg.) & Aff. & Yes, I will. & No, I will. \\
Don't tell him about it. & Neg. & No, I won't. & Yes, I won't. \\
\hline
\end{tabular}

3.4. IN RESPONSES TO STATEMENTS. The response words yes and no may occur as attention signals in reply to a statement. In Korean, yes and no mean "agreement" and "disagreement" respectively with the idea or opinion expressed in the preceding statement.

\begin{tabular}{l|c|c|l}
\hline \multicolumn{1}{c|}{ STIMULUS SENTENCE } & \multirow{2}{c}{ SACtatement } & \multicolumn{2}{c}{ RESPONSE } \\
\cline { 3 - 4 } (Aff.) & Aff. & Yes, he is. & Yes, he is. \\
He is leaving for Europe soon Neg. & No, he isn't. & No, he isn't. \\
\hline (Neg.) & Aff. & Yes, he is. & No, he is. \\
He is not very healthy. & Neg. & No, he isn't. & Yes, he isn't. \\
\hline
\end{tabular}

3.5. IN RESPONSES TO ALTERNATIVE QUESTIONS. Questions involving the alternative connector "or" do not require yes-no answers, either in English or in Korean. However, 
Korean speakers learning English often tend to use yes or no in the beginning of responses in English conversation, their selection of yes or no being based on the second part of alternative questions.

Two factors, one from English and the other from Korean, may be considered as the reasons for these mistakes. The structural similarity between alternative questions and yes-no questions in English draws the primary attention of Korean learners of English, while the distinction between the intonation patterns (rising-and-falling intonation for the alternative question, and rising intonation for the yes-no question) is one of the difficult phases for them to recognize. The following pairs of examples illustrate such confusing formal similarity.

\section{Example A)}

Alternative: Do you like coffee (A) or tea? ( ()

(Asking to choose.)

Yes-No: Would you like to have a cup of coffee or tea? ( $)$

(Asking about the desire for drinking something.)

\section{Example B)}

Alternative: Do you like to eat ice cream ( $)$ or cookies? ( ) Yes-No: Do you like to eat ice cream and cookies? ( 1 )

In Korean, on the other hand, alternative questions consist of two separate yes-no questions. The alternative adverb "or" occurs in the beginning of the second question functioning as a sentence linker or sequence signal. Although the pause between these two sentences may be shorter than that between two other types of sentences, each sentence is formally marked by a question inflectional ending:

\section{You coffee like-infl.? Or tea like-infl.? ${ }^{9}$}

In the following chart, the sample responses in the Korean column represent only the erroneous patterns frequently used by Korean speakers learning English in English conversation; they do not represent the patterns used in Korean conversation, 10 since, as has been already pointed out in the beginning of the present subsection, yes or no is not required for Korean alternative questions any more than in English.

${ }^{9}$ A pattern similar to the English alternative construction "You coffee or tea likeinfl.?" may occur in Korean only in unnatural translations from foreign languages such as English and French.

${ }^{10}$ This is an exception to the previous statement made in Section 3 that Korean examples represent both in the se charts. 


\begin{tabular}{|c|c|c|c|}
\hline \multirow{2}{*}{\begin{tabular}{r|} 
STIMULUS SENTENCE \\
Alternative Question
\end{tabular}} & \multirow{2}{*}{ FACT } & \multicolumn{2}{|c|}{ RESPONSE } \\
\hline & & English & Korean \\
\hline (Aff.) & & & \\
\hline Do you like coffee or tea? & Coffee & I like coffee. & No, I like coffee. \\
\hline Do you like tea or coffee? & Coffee & I like coffee. & Yes, I like coffee. \\
\hline (Neg.) & & & \\
\hline $\begin{array}{l}\text { Don't you like grapes or } \\
\text { grapefruit? }\end{array}$ & $\begin{array}{l}\text { Grape- } \\
\text { fruit }\end{array}$ & $\begin{array}{l}\text { I don't like } \\
\text { grapefruit. }\end{array}$ & $\begin{array}{l}\text { Yes, I don't like } \\
\text { grapefruit. }\end{array}$ \\
\hline $\begin{array}{l}\text { Don't you like grapefruit } \\
\text { or grapes? }\end{array}$ & $\begin{array}{l}\text { Grape- } \\
\text { fruit }\end{array}$ & $\begin{array}{l}\text { I don't like } \\
\text { grapefruit. }\end{array}$ & $\begin{array}{l}\text { No, I don't like } \\
\text { grapefruit. }\end{array}$ \\
\hline
\end{tabular}

4. SUMMARY OF PROBLEMS.

In responses to affirmative sentences, there is no special problem either in recognition or production except to the questions involving the word mind as a verb.

In responses to negative sentences, Korean speakers will be confused in understanding the meaning of English yes and no unless these responses are followed by explanatory statements. This problem, however, will soon disappear when production problems are eliminated.

The following are the focuses upon which the learner's attention should be centered in production:

1.) In responses to yes-no questions, commands, and statements, in the negative form:

a. To ignore the affirmative or negative status which appears in the form of the stimulus sentence.

b. To depend upon the status of the fact according to which the explanatory part of the response is to be formed.

c. To use the response word which is opposed to the one which may be used in Korean conversation.

2.) In responses to questions involving the word mind as a verb:

a. To reply "No...." always. (Assuming that the answerer would be always willing to permit whatever the speaker wants to do in an ordinary social situation.)

b. To remember that yes and no do not always mean "please" and "don't" respectively.

3.) In responses to alternative questions:

a. To remember that alternative questions are not yes-no 
questions, but supplement questions.

b. Not to put in any response word.

\section{LESSON PLANS.}

In the preceding section, problems for Korean speakers learning the English uses of the response words yes and no have been presented rather theoretically. The present section deals with some lesson plans to be used in actual classroom teaching to solve those problems.

The basic key lies in repetitive practice based on effective materials and methods. The statement made by Lado that "to learn a new language one must establish orally the patterns of the language as subconscious habits"11 is especially true with such words as yes and no, which are extremely simple for Korean speakers to learn as vocabulary items but which make the students unaware of the problems that appear in actual use of the words in English conversation.

With the above idea in mind, the exercises below focus on the response patterns to be practiced. The exercises consist of three parts:

Part I. The Primary Step: Exercises of independent response forms not preceded by any response-eliciting sentence.

Part II. The Intermediate Step: Exercises of response patterns in relation to specific types of stimulus sentences.

Part III. The Advanced Step: Review and practice of all the response patterns previously drilled, through conversations involving various types of stimulus sentences.

\section{PART I. THE PRIMARY STEP}

(Short Response Forms with Yes and $\mathrm{No}$ )

Suggestions to the teacher:

1. The teacher says each response form. The students repeat the same response form after the teacher.

2. The teacher assigns a specific response form: "Form A.1." or "Form B.2." The teacher then says the pronoun subject

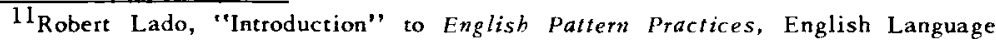
Institute Staff. (Ann Arbor: University of Michigan Press, 1958).

12 There is no pronunciation difficulty, since Korean has sounds and sound sequences similar to those of English for yes and no. There is no difficulty in acquiring and retaining the words yes and no in the vocabulary inventory, since Korean has the corresponding words ne and aniyo. 
of a response. The students say the whole response form using the subject given. Continue.

3. The teacher assigns a specific pronoun subject; "we" or "he." The teacher then says the response form to be practiced. Continue.

4. Use similar methods in assigning different tenses.

5. The above steps may be taken between the teacher and the whole class, or between the teacher and individual students.

6. Explain the difference between the complete (uncontracted) negative form and the contracted negative form: "formal vs. informal or colloquial."

7. This exercise chart can be useful for the students in the later exercises as a reference list.

Affirmative Responses

FORM A.1.

$Y E S$-SUBJ.-BE

Yes, I am (was).

Yes, he is (was).

-she, it-

Yes, you are (were).

-we, they-

FORM A.2.

YES-SUBJ.-AUX.

Yes, I do (did).

-you, we, they-

Yes, he does (did).

-she, it-

Yes, I have (had).

-you, we, they-

Yes, he has (had).

-she, it-
Negative Responses

FORM B.1.

$N O$-SUBJ . $-B E-N O T$

No, I am (was) not.

No, he is (was) not.

-she, it-

No, you are (were) not.

-we, they-

FORM B.2.

NO-SUBJ.-AUX. NOT

No, I do (did) not.

-you, we, they-

No, he does (did) not.

-she, it-

No, I have (had) not.

-you, we, they-

No, he has (had) not.

-she, it-
Contracted Neg. Responses FORM C.1.

NO-SUBJ.-BE $N^{\prime} T$

No, I'm not (wasn't) ${ }^{13}$

No, he isn't (wasn't).

-she, it-

No, you aren't (weren't).

we, they-

FORM C.2.

$N O$-SUBJ.-AUX. $N^{\prime} T$

No, I don't (didn't).

-you, we, they-

No, he doesn't (didn't).

-she, it-

No, I haven't (hadn't).

-you, we, they-

No, he hasn't (hadn't).

-she, it-

\footnotetext{
13 The difference between the contracted form "I'm not" and other ordinary contracted forms such as "wasn't" and "weren't" has to be pointed out to the students inconnection with item 6 in "Suggestions to the teacher."
} 
Affirmative Responses

FORM A.2.

Yes, I can (could).

-you, we, he,

she, it, they-

Yes, I may (might).

-you, we, he,

she, it, they-

Yes, I shall (should).

-you, we, he,

she, it, they-

Yes, I will (would).

-you, we, he,

she, it, they-
Negative Responses

FORM B.2.

No, I cannot (could not).

-you, we, he,

she, it, they-

No, I may (might) not.

No, I must not.

No, I can (could) not.

-you, we, he,

she, it, they-

No, I shall (should) not.

-you, we, he,

she, it, they-

No, I will (would) not.

-you, we, he,

she, it, they-
Contracted Neg. Responses

FORM C.2.

No, I can't (couldn't).

-you, we, he, she, it, they-

No, I mustn't.

No, I can't (couldn't $)^{14}$

-you, we, he,

she, it, they-

No, I -.- (shouldn't).

-you, we, he, she, it, they-

No, I won't (wouldn't).

-you, we, he, she, it, they-

PART II. THE INTERMEDIATE STEP

(Responses to Specific Stimulus Sentences)

Exercises for Part II are divided into five units. The same methods of pattern practice can be used in all five units.

Suggestions to the teacher:

1. (Teacher and class.) The teacher assigns a specific response word or a status.

a) The teacher gives questions: first in the affirmative, next in the negative. The class reply in the affirmative.

b) The teacher gives questions: first in the negative, next in the affirmative. ${ }^{15}$ The class reply in the negative.

2. (Teacher and individual students.) The teacher assigns a specific response word or a status.

a) The teacher gives a question in the affirmative and one in the negative to each student. Student replies in the negative.

${ }^{14}$ The various forms of negative responses to the sentences involving the word may have to be explained to the students.

${ }^{15}$ The purpose of raising questions in the affirmative and negative successively is to indicate clearly to the students that the status in the stimulus sentence is irrelevant selection of response words in English. 
b) The teacher gives a question in the negative and one in the affirmative to each student. Student replies in the affirmative.

3. (Teacher and individual students.) The students select the response word.

a) The teacher asks each student a question in the affirmative. Student replies with his own selection of the status.

b) The teacher asks each student a question in the negative. Student replies with his own selection of the status. ${ }^{16}$

4. (Pairs of students.) The students select the response word.

a) One student gives a question to the next student. The student questioned replies with his own selection of the status.

b) The answerer above gives a question in turn to a third student. The student questioned replies with his own selection of the status, and then gives a question to another student. Continue.

Note: In the above suggestions, questions have been used as representative examples of response-eliciting sentences for the sake of convenience. Therefore, the words "questions" and "asks questions," etc., are to be interpreted as "statements" and "makes statements," etc., according to each specific problem in the following exercises.

\footnotetext{
${ }^{16}$ The teacher has to be careful in selection of questions when the students are free to choose the status of their responses. Avoid such questions as "Did you enjoy your trip to Europe last year?" (to a student who has never had such a trip) or "Do you like your teacher?" (which would usually elicit only an affirmative reply). The questions for this step, therefore, have to be related to the ordinary environments of students' daily life in general so that they may respond according to the real facts or happenings in their life.
} 
EXERCISE 1: RESPONSES TO SIMPLE YES-NO QUESTIONS.

A) The Response Form: "Yes-Subj.-Be"-"No-Subj.-Be-Not"

Are you a student?

Aren't you a student?

Are you all students?

Aren't you all students?

Is he going to the concert tonight?

Isn't he going to the concert tonight?
Yes, I am.

No, I am not. No, I'm not.

Yes, we are.

No, we are not. No, we aren't

Yes, he is.

No, he is not. No, he isn't.

(Continue: Also in the past tense and in the negative form.)

1. Am I a teacher?

2. Are we from England?

3 . Is she a college student?
4. Is it all right?

5 . Is the book interesting?

6. Are Mary and John working?

B) The Response Form: "Yes-Subj.-Aux."-"No-Subj.-Aux.-Not"

Do you like the English course?

Don't you like the English course?

Does he study hard?

Doesn't he study hard?

Can he swim?

Can't he swim?
Yes, I do.

No, I do not. No, I don't.

Yes, he does.

No, he does not. No, he doesn't.

Yes, he can.

No, he cannot. No, he can't.

(Continue: Also in the past tense and in the negative form when possible.)

1. Do I speak too fast?

2. Does Mary type very fast?

3. Can we get there in time?

4. Can she sing well?

5. Have you ever been in Europe?
6. Will you join us in the game?

7. Will the book come out soon?

8. Shall I check it?

9. Shall we leave now?

10. May I open the door?

Note: The usual responses for questions 8,9 and 10 would be as follows:
8: Yes, please.
No, never mind.
9: Yes, we'd better leave.
10: Yes, you may.
No, let's stay a little longer.
No, you cannot. No, you must not.

\section{RESPONSES TO SIMPLE YES-NO QUESTIONS: SUPPLEMENT.}

Responses to questions which contain the word "mind" as a verb:

The Response Form: "No...." (DO NOT SAY YES when the specific thing, action, or situation in question is "all right" with you.) 
Do you mind if I bring one of my friends with me?

Do you mind my cigar?

Do you mind my singing?

Would you mind shutting the door?
No, not at all.

No, not a bit.

No, please go ahead.

No, I'd be glad to.

(Continue: More practice for simple question forms.)

1. Would you mind if I come back tonight?

2. Would you mind typing this up for me immediately?

3. Would you mind if I ask you some personal questions?

4. Didn't you mind when the girl was talking about your brother?

5. Did you mind my frequent calls at your home during the vacation?

6 . Do you mind carrying this heavy thing for me? 
EXERCISE 2: RESPONSES TO COMPLEX YES-NO QUESTIONS.

A) The Response Form: "Yes-Subj.-Be"-"No-Subj.-Be-Not"

You are from Seoul, aren't you?

You are not from Seoul, are you?

They are studying at the library, aren't they?

They are not studying at the library, No, they are not. No, they aren't. are they?

(Continue: Also in the past tense when possible and in the negative statement form.)

1. We are all Koreans, aren't we?

2. I am speaking English, am I not?

3. Helen is beautiful, isn't she?

4. Your sister is a good painter, isn't she?

5 . Your mother's eyes are blue, aren't they?

B) The Response Form: "Yes-Subj.-Aux."-"No-Subj.-Aux.-Not"

You like music, don't you?

You don't like music, do you?

You will come with us, won't you?

You won't come with us, will you?
Yes, I do.

No, I do not. No, I don't.

Yes, I will.

No, I will not. No, I won't.

(Continue: Also in the past tense and in the negative statement form when possible.)

1. I talk too loud, don't I?

2. We have to hurry, don't we?

3. He can speak Russian, can't he?

4. She can go with me, can't she?

5. They will come after us, won't they?

6. The man works carelessly, doesn't he? 
EXERCISE 3: RESPONSES TO COMMANDS.

A) The Response Form: "Yes-Subj.-Be"-"No-Subj.-Be-Not" (This form rarely occurs in ordinary situations.) Examples:

\section{Command}

Be good.

Be ambitious.

\section{Response}

Yes, I am (always).

No (I'm already tired of life).

B) The Response Form: "Yes-Subj.-Aux." -"No-Subj.-Aux.-Not"

\section{Command}

Do your homework now.

Don't tell him about it.

\section{Response}

Yes, I will.

No, I will not. No, I won't.

(Continue: Also in the negative form when possible.)

1. Tell me about your trip.

2. Go with him tomorrow.

3. Please give me a ring tonight.

4. Bring your passport with you when you come to see me next.

5. Please have some cookies. (Thank you. No, thank you.)

Note: The phrase "All right" can be substituted for either yes or no: for yes in response to affirmative commands, for no in response to negative commands. 


\section{EXERCISE 4: RESPONSES TO STATEMENTS.}

Suggestions to the teacher: The following devices for practice may be helpful to the students, since statements which elicit the response words yes and no as attention signals usually occur in more complex forms than those of other questions or commands:

1. The teacher makes a statement.

2. Then points out to the students the subject and the verb on which their response is to be based.

3. After some practice, let the students be independent of such help.

A) The Response Form: "Yes-Subj.-Be"-"No-Subj.-Be-Not"

\section{$\underline{\text { Statement }}$}

I understand that he is leaving for Europe soon.

I think Mary is studying at the library.
Response

Yes, he is.

No, he isn't. (He has postponed it to next year.)

Yes, she is. (I have just seen her there.)

No, she isn't. (She went to the concert.)

(Continue: Also in the opposite tense and status when possible.)

1. I believe Mrs. Hale is sick.

2. You were not at home when I called yesterday.

3. I imagine that Joan is very anxious about the results of her research.

4. John is not very happy these days.

5 . I heard that the concerts were very good.

B) The Response Form: "Yes-Subj.-Aux."-"No-Subj.-Aux.-Not"

\section{$\underline{\text { Statement }}$}

They say w'e have to finish it by by this weekend.

I remember that Jane already spoke Spanish last year.

\section{Response}

Yes, we do. No, we don't.

Yes, she did. No, she didn't.

(Continue: Also in reconstructed similar sentences adopting different time or tense and status.)

1. He practiced in the laboratory this morning.

2. It seems that it's going to rain.

3. I never realized that she was that old. She looks so young.

4. I can't afford the time to listen to all her stories. She lalks too much.

5. Look at the moon and the stars. It is a lovely night. It makes me feel homesick. 


\section{EXERCISE 5: RESPONSES TO ALTERNATIVE QUESTIONS.}

Suggestions to the teacher: Explain to the students about the difference between an alternative question and a yes-no question containing an alternative construction. The most characteristic difference is in the intonation: alternative questions and with a falling intonation; yes-no questions involving alternative constructions end with a rising intonation.

A) The Response Form-To Alternative Questions: "Subj.-V..." "Subj.-V.Not..." -DO NOT USE EITHER YES OR NO.

Are you from Korea, or Japan?

Are you in Graduate School, or Medical School?

\section{I'm from Korea.}

I'm not in either of them. I'm just visiting some classes in both. ${ }^{17}$

(Continue: Also in different statuses, tenses and subjects.)

1. Are they professors, or visitors?

2. Is she going to sing at a concert, or at a recital?

3. Do you like novels, or plays?

4. Is it a biography, or an autobiography?

5. Are we now in Ohio, or still in Michigan?

6 . Have you bought a radio, or a television?

7. Shall we take a walk, or shall we listen to music here?

8. Did you lose it, or was it stolen?

B) The Response Form-To Yes-No Questions involving alternative constructions: "Yes-Subj.-V."-"No-Subj.-V.-Not"-USE YES OR NO.

Do you have a pen or a pencil?

Are you going to Washington or New York this spring?

Would you like to have a cup of No, thank you. coffee or tea?

(Continue: Also in other similar sentences adopting different tenses, statuses, nouns and pronouns.)

1. Is he going to Europe or South America again this year?

2. Does Mary have an organ or a piano?

3 . Do you have enough time to read papers or magazines in the evening?

4. May I open a window or a door?

5. Shall we discuss it with mother or father?

6. Will John arrive here tomorrow or the day after?

7. Don't you need one more waiter or waitress at your restaurant?

8. Can they speak French or German? 


\section{PART III. THE ADVANCED STEP \\ (Conversations)}

Suggestions to the teacher:

Place: An informal place is preferable-somewhere outside the classroom.

Material: Some pictures or films would be helpful for raising topics and for natural responses, if shown before starting, or during, the conversations. Some refreshments would supply good stimuli for topics.

Topic: "Recreation and hobbies" "School life"
"Home life"
"Future plans"

Method: First, the teacher helps the students in raising or changing topics. Later, let the students be independent of help as Iong as they can carry on their conversations in the simplest forms of the response-eliciting sentences and of the responses.

\section{(Example)}

Teacher: Do you think this is a better place to study than our classroom?

Student A: Yes, I do, because this is a conversation class.

Student B: Yes, I think so, too.

Teacher: I agree with you. Now, would you like to have some cookies?

Student C: Yes, thank you. We always like cookies, don't we?

Teacher: What would you like to drink? Coffee or tea?

Student D: I would like to have tea.

Student E: I want coffee.

Teacher: What would you like, Ockhee? Tea or coffee?

Ockhee: Tea, please.

Student E: Don't you like coffee?

Ockhee: Yes, I do. But I drink it only at night when I have to stay up late.

Student F: Do you study very late every night?

Ockhee: No, not every night.

Student G: Ockhee always studies hard.

Student H: Yes, she does.

Student I: Isn't she planning to go abroad after graduation?

Student J: Yes, she is. Are you going to America, Ockhee?

Ockhee: Yes, I am.

Student A: She is a lucky girl, isn't she?

Student B: Yes, she is. I wish I could go, too.

Student C: Ockhee, don't forget about us while you are in America.

Ockhee: No, I won't.

Student H: Would you mind if I close the window? (It's a cold day.)

Students: No, not at all.

Teacher: Well, refreshments are ready. Would you like to see some of my pictures or color slides?

Students: Yes. We would like to see your pictures first.

Teacher: All right. 